\title{
Dutch Health NGO granted Official Relations with World Health Organisation
}

Health Action International (HAI), an Amsterdam based non-government organisation (NGO), has been granted Official Relations with the World Health Organisation (WHO) at the recent meeting of the Executive Board of the World Health Assembly in Geneva.

With Regional offices in Africa, Asia Pacific, Europe and Latin America, HAI was founded in 1981 and campaigns globally for equity in health and for all people to have access to the essential medicines they need, and that those medicines be used rationally. HAI base their advocacy on research excellence and evidence and aim to capacity-build civil society, often in poor country settings, to campaign for access to medicines and have a comprehensive work programme in partnership with WHO.

"We are absolutely delighted that at last our work is being recognised by the World Health Organisation", said HAI's Global Director, Tim Reed, "it is something we have strived to achieve for a long time, and brings prestige and legitimacy to our work".

HAI does not accept donations from the pharmaceutical industry and is primarily funded by governments' overseas development agencies (Netherlands, UK, Sweden, Finland and Denmark) and charitable foundations.

"Recognition of HAI's work by WHO further justifies the confidence that our donors, and particularly the Dutch government have always placed in us", said Dr. Reed, adding "I can promise you that we will re-double our efforts to bring about justice in global health and equity in access to essential medicines throughout the world".

For more information on the work of HAI visit www.haiweb.org.

Sophie Bloemen

European Project Officer

Health Action International (HAI) Europe

Jacob van Lennepkade 334T

1053 NJ Amsterdam

The Netherlands

Tel.: +31206892943

Fax: +31 206855002

E-mail: sophie@ haiweb.org

Health Action International (HAI) is an independent, global network working to increase access to essential medicines and improve their rational use. 